\title{
Artificial cultivation and nutritional evaluation of proteins from a wild Ganoderma gibbosum strain
}

\author{
Changxia Yu ${ }^{\mathrm{a}}$, Liping $\mathrm{Xi}^{\mathrm{a}}$, Yan Zhao ${ }^{\mathrm{a}, *}$, Aiping Feng ${ }^{\mathrm{a}}$, Lei Zha ${ }^{\mathrm{a}}$, Huanling Yang ${ }^{\mathrm{a}}$, Mingjie Chen $^{\mathrm{a}, *}$, \\ Yaru Zhang ${ }^{\mathrm{a}, \mathrm{b}}$, Ling Zhang ${ }^{\mathrm{a}, \mathrm{c}}$ \\ ${ }^{a}$ Institute of Edible Fungi, Shanghai Academy of Agricultural Sciences, Shanghai 201403 China \\ b College of Food Sciences and Technology, Shanghai Ocean University, Shanghai 201306 China \\ c College of Agricultural, Anshun University, Anshun 561000 China
}

*Corresponding authors, e-mail: jiandan289@126.com, mjfungi@126.com

Received 21 Apr 2020

Accepted 19 Jul 2020

\begin{abstract}
Ganoderma gibbosum is a medicinal fungus widely distributed in China, but the scarcity of its wild resources has limited its application and potential economic value. In this research, we collected a macrofungus from the wild, isolated using tissue culture technique, and identified by morphological characteristic analysis combined with ITS sequencing and homology-based phylogenetic analysis. A DNA fragment of approximately 650 bp was obtained and the fungus was identified as G. gibbosum. Furthermore, the fungus was cultured in liquid medium and artificially cultivated for fruiting body development. The crude protein contents and amino acid compositions of the mycelia, artificially cultivated and wild fruiting bodies were systematically evaluated to assess the nutritional value. Protein quality was evaluated by calculating the amino acid score (AAS), chemical score (CS), score of ratio coefficient of amino acids (SRC) and essential amino acid index (EAAI), referring to the most recent version of the international amino acid reference patterns. The results revealed that 17 kinds of amino acids were detected, and the essential amino acid contents were superior to the WHO/FAO reference protein pattern value in the hydrolysates of samples. The most abundant essential amino acid in mycelia was Lys, whereas that in both artificially cultivated and wild fruiting bodies was Met. The SRC values were between 25.30 and 69.84, and the EAAI values were between 75.15 and 94.43 , which basically conformed to the requirements of current international reference patterns. The study provides a scientific basis for further utilization of this fungus.
\end{abstract}

KEYWORDS: Ganoderma gibbosum, ITS identification, artificial cultivation, protein nutritional value, amino acid composition, medicinal fungus

\section{INTRODUCTION}

Ganoderma gibbosum (Blume \& T. Nees) Pat. which belongs to the Ganodermataceae family [1] is mainly distributed in Jiangsu, Zhejiang, Hainan and other provinces of China [2]. There are abundant resources of Ganodermataceae fungi in China that are used as traditional Chinese medicines, and many species have medical and economic value [3]. The antibacterial, anticancer, antiviral, antioxidant, immune regulatory and sedative properties of Ganoderma make these fungi popular among the public. G. gibbosum is a medicinal fungus that not only presents a medical value similar to that of Ganoderma applanatum (Pers.) Pat. but also is considered useful for treating stomach diseases in Hainan province of China [4]. The wild resources of $G$. gibbosum are currently scarce, and there has been little research on this fungus. Chen et al [5] studied the characteristics of mycelial cultures of G. gibbosum by measuring the mycelial growth rate and biomass. Zhang et al [6] explored the culture characteristics of wild $G$. gibbosum by cultivating its mycelia on solid plates and under artificial domestication cultivation, and they found that fruiting bodies could form on all three kinds of culture substrates. Many studies have focused on the biological characteristics of $G$. gibbosum mycelia, while research on the nutritional value of the proteins of G. gibbosum has rarely been reported.

The evaluation of protein quality is mainly based on the reference protein equivalent pattern [7], obtained by analyzing parameters such as the amino acid score (AAS), chemical score (CS), essential amino acid index (EAAI), ratio coefficient of amino acids (RC) and score of ratio coefficient of amino acids (SRC). The systematic evaluation of protein quality using the above parameters has not 


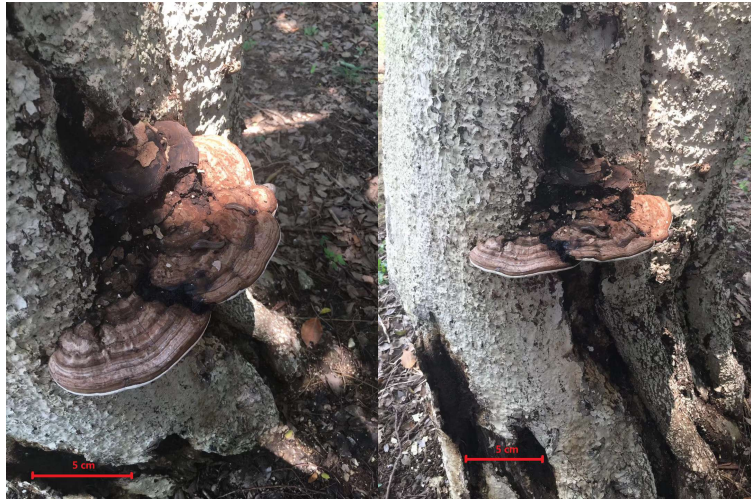

Fig. 1 Morphology of wild macrofungi.

yet been reported in G. gibbosum as a wild medicinal fungal resource. Chen et al [8] analyzed and compared the amino acid contents of the fruiting bodies of Ganoderma in Fujian province and found that the total amino acid content in G. gibbosum was lower than that in G. applanatum, but the proportion of essential amino acids was much higher; however, the amino acid characteristics and protein quality were not studied. In this study, mycelia, artificially cultivated fruiting bodies and wild fruiting bodies of $G$. gibbosum were used as the research materials, and their protein quality was analyzed by measuring the crude protein content and amino acid composition. The purpose of this work was to evaluate the nutritional value of the protein of G. gibbosum, thus providing a theoretical reference for further utilization of this fungus.

\section{MATERIALS AND METHODS}

\section{Sample collection}

In July 2018, a large fungus was found on a beech tree (Zelkova serrata (Thunb.) Makinoz) at the Shanghai Academy of Agricultural Sciences (SAAS), Shanghai, China (Fig. 1). This place used to be wild areas before the SAAS moved in. Furthermore, cultivation of G. gibbosum isolated from this area has never been reported. After isolation, fungus has been preserved on PDA medium at the Edible Fungi Institute of the SAAS by tissue culture and designated as SS.

\section{Culture medium}

Solid medium: One litre of potato dextrose agar (PDA) medium was composed of $200 \mathrm{~g}$ peeled potato extract, $20 \mathrm{~g}$ dextrose, and $20 \mathrm{~g}$ agar. The PDA medium was sterilized for $20 \mathrm{~min}$ at $121^{\circ} \mathrm{C}$ and aseptically poured into a petri-dish.
Liquid medium: One litre of potato dextrose (PD) medium was composed of $200 \mathrm{~g}$ peeled potato extract, and $20 \mathrm{~g}$ dextrose, and the PD medium was sterilized for $20 \mathrm{~min}$ at $121^{\circ} \mathrm{C}$.

\section{Morphological identification}

The morphological characteristics of the wild fungi, including the shape, size, color, stipe, cap, and ring pleats of the fruiting bodies and the size and color of the spores, were observed.

\section{Molecular identification}

Total DNA extraction: For preservation, the fungal mycelia were subcultured on PDA plates. After incubation for 10 days at $25^{\circ} \mathrm{C}$, mycelia were collected and thoroughly ground in liquid nitrogen using a mortar, after which DNA was extracted with the cetyltrimethylammonium bromide (CTAB) method [9].

PCR amplification was performed using the primers ITS1 (5'-TCCGTAGGTGAACCTGCGG-3') and ITS4 ( $5^{\prime}$-TCCTCCGCTTATTGATATGC- $\left.3^{\prime}\right)$. The reaction system included $12.5 \mu \mathrm{l}$ of $2 \times$ Easy Taq Mix, $1 \mu l$ of each primer, $1 \mu l$ of template DNA, and $9.5 \mu \mathrm{l}$ of $\mathrm{ddH}_{2} \mathrm{O}$. PCR amplification was performed as follows: predegeneration at $94^{\circ} \mathrm{C}$ for $3 \mathrm{~min}$, followed by 35 cycles of denaturation at $94^{\circ} \mathrm{C}$ for $30 \mathrm{~s}$, annealing at $55^{\circ} \mathrm{C}$ for $30 \mathrm{~s}$ and extension at $72{ }^{\circ} \mathrm{C}$ for $1 \mathrm{~min}$ and a final extension at $72^{\circ} \mathrm{C}$ for $10 \mathrm{~min}$. After the PCR product was detected by $1.0 \%$ agarose gel electrophoresis, the target bands were sequenced by Sangon Biotech (Shanghai) Co., Ltd. The obtained internal transcribed spacer (ITS) sequence was analyzed with DNAMAN software and compared with the DNA database with the BLAST tool on the NCBI website, and the most homologous sequences were downloaded. A phylogenetic tree was constructed using the neighbor-joining method with MEGA 6.0 software, and the bootstrap parameter was set to 1000 .

\section{Mycelia collection}

Fungal mycelia were subcultured on a PDA plate. After incubation for 7 days at $25^{\circ} \mathrm{C}$, the culture was transferred to $250 \mathrm{ml}$ flasks containing $100 \mathrm{ml}$ of PD medium, and the flasks were incubated at $25^{\circ} \mathrm{C}$ with shaking at $150 \mathrm{rpm}$ for 12 days. Mycelia were collected, washed with $\mathrm{ddH}_{2} \mathrm{O}$, blotted with filter paper to remove excess moisture, dried at $60^{\circ} \mathrm{C}$ overnight, ground immediately thereafter using a mill (Retsch ultracentrifugal mill and sieving machine, Haan, Germany), and reserved after sieving through a 40 mesh [10]. 


\section{Fungal cultivation and preparation}

The main substrate culture formulation for the SS fruiting bodies was composed of $78 \%$ sawdust, $20 \%$ wheat bran, $1 \%$ gypsum, $0.5 \%$ corn meal, and $0.5 \% \mathrm{KH}_{2} \mathrm{PO}_{4}$ by weight/weight. The moisture content of the culture substrate was maintained at $60-65 \%(\mathrm{w} / \mathrm{w})$. The homogenized substrate $(900 \mathrm{~g})$ was placed in polyethylene bags $(17 \mathrm{~cm} \times 33 \mathrm{~cm} \times 0.03 \mathrm{~cm})$. The culture substrate was added to a total of eighty polyethylene bags as replicates. Then, the culture substrate was sterilized under atmospheric pressure at $121^{\circ} \mathrm{C}$ for $2 \mathrm{~h}$. The sterilized substrate was inoculated with $20 \mathrm{~g}$ of fully colonized spawn, which was then cultured in a darkened ventilated spawn running room at $25^{\circ} \mathrm{C}$ with $60-62 \%$ relative humidity until mushroom mycelium running was complete (approximately 30 days). Thereafter, the fungal mycelia entered the ripe stage, and culture continued for 10 days; when the mycelia became physiologically mature, the culture bags were removed. Fungal fruiting bodies were grown at $25^{\circ} \mathrm{C}$ with $85-95 \%$ relative humidity in the mushroom growing room. Samples of the fruiting bodies were harvested at the fruiting developmental stages, dried at $60^{\circ} \mathrm{C}$, and then ground into a fine powder (40 mesh) using a mill. The wild fruiting bodies were similarly treated as described for the artificially cultivated ones.

\section{Determination of the crude protein content}

The crude protein content was measured according to China National Standard GB5009.5-2016, "Determination method of protein in food", by Kjeldahl determination.

\section{Assay of amino acids}

Powdered samples (60 mg) were suspended in $5 \mathrm{ml}$ of $6 \mathrm{~N} \mathrm{HCl} \mathrm{(36 \% )} \mathrm{and} 20 \mu \mathrm{l}$ of phenol, after vacuum treatment applied, the ampere tube was filled with pure nitrogen and then sealed. Hydrolysis was performed in a drying oven at a constant temperature of $110^{\circ} \mathrm{C}$ for $22 \mathrm{~h}$. After the hydrolysate was cooled at ambient temperature and transferred to a $25 \mathrm{ml}$ volumetric flask, a $1 \mathrm{ml}$ aliquot was transferred to a $5 \mathrm{ml}$ volumetric flask and dried at $40-50^{\circ} \mathrm{C}$ two times until the residues were completely evaporated. Then, the extracted solids were redissolved in buffer ( $\mathrm{pH} 2.2$ ) to a final volume of $1 \mathrm{ml}$, the solution was centrifuged at $12000 \times \mathrm{g}$ for $25 \mathrm{~min}$, and the supernatant was filtered with a filter membrane $(0.22 \mu \mathrm{m}$ cellulose filter, Millipore, Shanghai, China) prior to analysis $[11,12]$. The amino acid

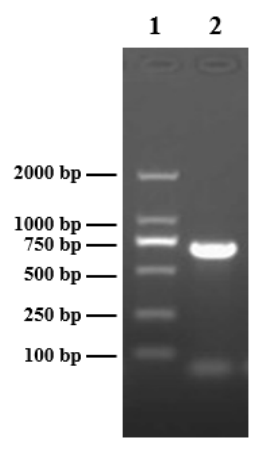

Fig. 2 PCR amplification results from wild fungi. Lane 1: DNA marker; lane 2: PCR amplification of ITS from mycelia of SS.

content using an L-8900 automatic amino acid analyzer (Hitachi Ltd., Japan) was determined.

\section{Nutritional evaluation of proteins}

The AAS was calculated according to the $\mathrm{WHO} /-$ FAO/UNU method [13]. The CS was calculated using the reference method recommended by FAO and Seligson and Mackey [14]. The EAAI was evaluated according to Oser $[15,16]$, and the RC and SRC were calculated according to $\mathrm{Zhu}$ and $\mathrm{Wu}$ [17].

\section{RESULTS}

\section{Morphological characteristics}

The fruiting body of the collected wild fungi was fan-shaped, extended laterally and had a flat cap, with a diameter of $15.2 \mathrm{~cm}$, a short diameter of $6.8 \mathrm{~cm}$, and a thickness of $2.9 \mathrm{~cm}$. The surface was reddish brown, with a concentric annulus and tumor-like protrusions. The orifice on the underside was white or yellow-white, and the tube was clearly visible, similar to the recorded characteristics of G. gibbosum. The spores of this fungus were brown, and the size was approximately $9 \mu \mathrm{m} \times 5 \mu \mathrm{m}$ under the light microscope examination.

\section{ITS analysis and construction of the phylogenetic tree}

Using the DNA of SS mycelia as the template for ITS region amplification, a DNA fragment of approximately 650 bp was obtained (Fig. 2), and the successfully amplified product bands were sequenced. Thereafter, using BLAST tools for comparison, the sequences with the highest homology were selected for analysis and to construct the phylogenetic tree (Fig. 3). The results showed that SS presented similarity to the Ganoderma genus and belonged 


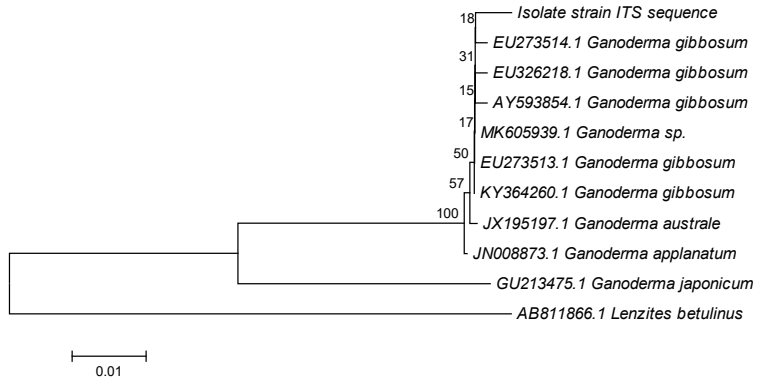

Fig. 3 Neighbor-joining (NJ) phylogenetic tree based on the rDNA ITS region sequence. Bar indicates 0.01 sequence divergence substitutions per nucleotide position.

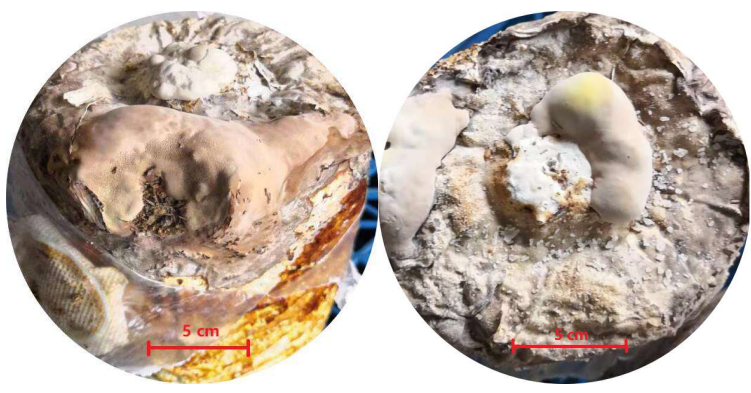

Fig. 4 Primordium formation in Ganoderma gibbosum under artificial cultivation.

to G. gibbosum, with 99\% homology. Combined with the observed morphological characteristics, the isolated SS was identified as G. gibbosum.

\section{Artificial cultivation}

G. gibbosum could grow normally in the cultivation medium, and the time required for the mycelia to completely fill the bag was approximately 30 days. After 10 days of further culture, the bags were removed for fruiting body formation, and the primordia formed for approximately one month (Fig. 4). Compared with the wild fruiting bodies, the artificially cultivated fruiting bodies exhibited a lighter color, softer texture and decreased thickness, which may be related to the age of the fruiting bodies, light conditions or cultivation substrate.

\section{Crude protein content}

The crude protein contents of the mycelia, artificially cultivated fruiting bodies and wild fruiting bodies were $26.00 \pm 0.40,14.13 \pm 0.10$ and $14.02 \pm 0.21 \mathrm{~g} / 100 \mathrm{~g} \mathrm{DW}$, respectively. The results showed that the mycelia exhibited the highest crude protein content and that the crude protein contents of the artificially cultivated and wild fruiting bodies
Table 1 Amino acid composition of the proteins of G. gibbosum.

\begin{tabular}{llrrr}
\hline \multirow{2}{*}{ Amino acid } & \multicolumn{3}{c}{ Content (mg/g DW) } \\
\cline { 2 - 5 } composition & \multicolumn{1}{c}{ CM } & \multicolumn{1}{c}{ AF } & \multicolumn{1}{c}{ WF } \\
\hline EAA & Thr & $12.99 \pm 0.14$ & $5.94 \pm 0.09$ & $4.82 \pm 0.10$ \\
& Lys & $18.11 \pm 0.27$ & $5.41 \pm 0.03$ & $3.56 \pm 0.13$ \\
& Leu & $15.64 \pm 0.18$ & $8.90 \pm 0.05$ & $5.43 \pm 0.14$ \\
& Ile & $8.08 \pm 0.10$ & $4.86 \pm 0.16$ & $1.83 \pm 0.04$ \\
& Met & $2.67 \pm 0.07$ & $30.15 \pm 0.36$ & $27.71 \pm 0.33$ \\
& Phe & $10.06 \pm 0.11$ & $4.96 \pm 0.08$ & $3.66 \pm 0.03$ \\
& Val & $13.87 \pm 0.18$ & $6.07 \pm 0.06$ & $4.32 \pm 0.09$ \\
\cline { 2 - 5 } & Total & $81.43 \pm 0.97$ & $66.28 \pm 0.26$ & $51.32 \pm 0.31$ \\
\hline NEAA & Asp & $21.87 \pm 0.27$ & $9.96 \pm 0.04$ & $7.29 \pm 0.16$ \\
& Ser & $12.99 \pm 0.14$ & $5.94 \pm 0.09$ & $4.82 \pm 0.10$ \\
& Glu & $32.68 \pm 0.37$ & $11.75 \pm 0.39$ & $6.96 \pm 0.21$ \\
& Gly & $12.75 \pm 0.19$ & $5.97 \pm 0.31$ & $4.20 \pm 0.08$ \\
& Ala & $17.64 \pm 0.26$ & $6.38 \pm 0.46$ & $4.64 \pm 0.12$ \\
& Cys & $1.40 \pm 0.11$ & $1.16 \pm 0.02$ & $0.54 \pm 0.02$ \\
& Tyr & $5.83 \pm 0.04$ & $2.25 \pm 0.14$ & $2.37 \pm 0.24$ \\
& His & $6.65 \pm 0.07$ & $2.07 \pm 0.06$ & $1.43 \pm 0.05$ \\
& Arg & $17.40 \pm 0.18$ & $4.09 \pm 0.15$ & $3.16 \pm 0.07$ \\
& Pro & $10.79 \pm 0.15$ & $4.72 \pm 0.17$ & $3.60 \pm 0.06$ \\
\cline { 2 - 5 } & Total & $139.80 \pm 1.72$ & $54.55 \pm 1.77$ & $38.73 \pm 0.66$ \\
\hline TAA & & $221.23 \pm 2.69$ & $120.83 \pm 1.67$ & $90.05 \pm 0.79$ \\
E/T & & $0.37 \pm 0.00$ & $0.55 \pm 0.01$ & $0.57 \pm 0.00$ \\
E/N & & $0.58 \pm 0.00$ & $1.22 \pm 0.04$ & $1.33 \pm 0.02$ \\
\hline
\end{tabular}

$\mathrm{CM}$, cultured mycelia; AF, artificially cultivated fruiting bodies; WF, wild fruiting bodies; EAA, essential amino acids; NEAA, nonessential amino acids; TAA, total amino acids; E/T, essential/total amino acids; $\mathrm{E} / \mathrm{N}$, essential/nonessential amino acids. Data were calculated from triplicated samples.

were similar.

\section{Conversion coefficient of nitrogen in protein}

It was determined that the total amino acid content of the mycelia accounted for $85.09 \%$ of the crude protein content, and the corresponding proportions in the artificially cultivated fruiting bodies and wild fruiting bodies were $85.51 \%$ and $64.23 \%$, respectively. The calculated conversion coefficients of nitrogen in protein in the mycelia, artificially cultivated fruiting bodies and wild fruiting bodies were $5.32,5.35$ and 4.02 , respectively, which were lower than the traditional conversion factor of 6.25 , suggesting that this coefficient shows some degree of specificity in different research fields [18].

\section{Assay of the amino acid composition}

The composition and content of amino acids were analyzed in the mycelia, artificially cultivated fruiting bodies and wild fruiting bodies. The three types of samples contained 17 common amino acids (tryptophan was not detected) (Table 1). The contents of total amino acids and essential amino acids were highest in the mycelia, and their contents in 
artificially cultivated fruiting bodies were higher than those in wild fruiting bodies. Glutamic acid was found to be the major amino acid in the mycelia, accounting for $14.77 \%$ of the total amino acids, whereas high levels of methionine were observed in artificially cultivated fruiting bodies and wild fruiting bodies, accounting for $24.95 \%$ and $30.77 \%$ of the total amino acids, respectively.

According to the ideal protein model factors proposed by the $\mathrm{FAO} / \mathrm{WHO}$, the ratio of essential amino acids to total amino acids (E/T) was approximately 0.40 , and the ratio of essential to nonessential amino acids $(\mathrm{E} / \mathrm{N})$ was greater than 0.60. The $\mathrm{E} / \mathrm{T}$ and $\mathrm{E} / \mathrm{N}$ in mycelia were 0.37 and 0.58 , respectively, which showed that the protein composition of the mycelia was close to the ideal protein model proposed by the FAO/WHO, belonging to the better-quality protein category. The $\mathrm{E} / \mathrm{T}$ $(0.55$ and $0.57,>0.40)$ and $\mathrm{E} / \mathrm{N}(1.22$ and 1.33 , $>0.60$ ) of both the artificially cultivated fruiting bodies and wild fruiting bodies were superior to the reference values, and the protein composition of the fruiting bodies of G. gibbosum suggested that they are an excellent source of protein.

\section{Composition of essential amino acids}

The nutritional value of proteins depends on the composition and proportion of the amino acids within them, especially the composition and proportion of essential amino acids. All three types of samples exhibited abundant essential amino acids (400.78-603.14 mg/g protein) (Table 2). The highest content of essential amino acids was found in wild fruiting bodies, followed by that in artificially cultivated fruiting bodies, while the content of essential amino acids in mycelia was lowest; all three materials showed markedly superior essential amino acid contents to the WHO/FAO reference protein pattern value $(350 \mathrm{mg} / \mathrm{g}$ protein). The content of essential amino acids in mycelia was inferior to the ovalbumin model value $(497 \mathrm{mg} / \mathrm{g}$ protein), while the contents in artificially cultivated fruiting bodies and wild fruiting bodies were superior to that value.

Methionine and cysteine were found to be the major essential amino acids in artificially cultivated fruiting bodies and wild fruiting bodies. Their contents accounted for approximately half of the total essential amino acids and were more than 7 times and 4 times the WHO/FAO reference value and the ovalbumin reference value, respectively. Lysine was the major essential amino acid in mycelia. The wild fruiting bodies exhibited higher levels of methionine and cysteine than the artificially cultivated fruiting bodies.

\section{Nutritional profile of amino acids in proteins}

The AAS, representing the percentage of a single essential amino acid in a tested protein sample in relation to the corresponding amino acid in the $\mathrm{FAO} / \mathrm{WHO}$ reference protein pattern, was the main index used to evaluate the nutritional value of the amino acid compositions in the current study. The closer the AAS to $100 \%$ and the closer the composition of amino acids to the standard model, the higher the nutritional value of protein. The lowest AAS is taken as the total AAS of the sampled protein, and the corresponding amino acid is also known as the first-limiting amino acid. Met+Cys were the first-limiting amino acids in mycelia, and Lys and Ile were the first-limiting amino acids in artificially cultivated fruiting bodies and wild fruiting bodies (Table 3). In addition, the AASs of other amino acids in the mycelia and artificially cultivated fruiting bodies were higher or closer to the FAO/WHO reference protein pattern. However, the AASs of Lys and Leu in wild fruiting bodies were much lower than those from the FAO/WHO reference protein pattern values. According to the AAS value, the composition and proportion of essential amino acids in artificially cultivated fruiting bodies were closer to the amino acid composition required by humans than those in wild fruiting bodies. It is worth noting that the AASs of Met+Cys in artificially cultivated fruiting bodies and wild fruiting bodies were much higher than the model values (741.24 and 892.47, respectively).

The CS is used to evaluate the proximity of the relative content of an essential amino acid in a tested protein to the relative content of the corresponding essential amino acid in the ovalbumin reference protein pattern. The closer the CS to $100 \%$ and the closer the composition of amino acids to the reference protein pattern, the higher the nutritional value of protein. A CS below 100\% indicates a limiting amino acid. Meanwhile, the amino acid that exhibits the lowest CS will be the first-limiting amino acid. Met+Cys, Phe+Tyr and Ile were the first-limiting amino acids in mycelia, artificially cultivated fruiting bodies and wild fruiting bodies, respectively (Table 3). Ile was the secondlimiting amino acid in mycelia and artificially cultivated fruiting bodies, whereas Lys was the secondlimiting amino acid in wild fruiting bodies. The CS of Ile in artificially cultivated fruiting bodies was $96.61 \%$ higher than that in wild fruiting bodies. 
Table 2 Essential amino acid composition of proteins in G. gibbosum.

\begin{tabular}{|c|c|c|c|c|c|}
\hline \multirow[t]{2}{*}{ Amino acid } & \multicolumn{5}{|c|}{ Content (mg/g protein) } \\
\hline & $\mathrm{CM}$ & $\mathrm{AF}$ & WF & $\mathrm{WHO} \mathrm{FAO}^{\mathrm{a}}$ & Ovalbumin $^{\mathrm{a}}$ \\
\hline Thr & $58.71 \pm 0.15$ & $49.22 \pm 0.80$ & $53.94 \pm 0.18$ & 40 & 51 \\
\hline Lys & $81.86 \pm 0.26$ & $44.80 \pm 0.74$ & $39.84 \pm 0.61$ & 55 & 64 \\
\hline Leu & $70.70 \pm 0.07$ & $73.73 \pm 0.15$ & $60.76 \pm 0.89$ & 70 & 88 \\
\hline Ile & $36.53 \pm 0.07$ & $40.22 \pm 0.11$ & $20.46 \pm 0.32$ & 40 & 66 \\
\hline Met+Cys & $18.43 \pm 0.26$ & $259.44 \pm 3.27$ & $312.37 \pm 3.59$ & 35 & 55 \\
\hline Phe+Tyr & $71.86 \pm 0.18$ & $59.78 \pm 0.75$ & $67.47 \pm 2.07$ & 60 & 100 \\
\hline Val & $62.69 \pm 0.04$ & $50.28 \pm 0.24$ & $48.29 \pm 0.15$ & 50 & 73 \\
\hline Total & $400.78 \pm 0.56$ & $577.47 \pm 3.98$ & $603.14 \pm 5.36$ & 350 & 497 \\
\hline
\end{tabular}

${ }^{a}$ WHO/FAO and ovalbumin reference protein pattern values. CM, cultured mycelia; AF, artificially cultivated fruiting bodies; WF, wild fruiting bodies. Data were calculated from triplicated samples.

Table 3 Nutritional profile of amino acids in the proteins of G. gibbosum.

\begin{tabular}{|c|c|c|c|c|c|c|c|c|c|}
\hline \multirow{2}{*}{$\begin{array}{l}\text { Amino } \\
\text { acid }\end{array}$} & \multicolumn{3}{|c|}{ AAS (\%) } & \multicolumn{3}{|c|}{ CS (\%) } & \multicolumn{3}{|c|}{$\mathrm{RC}$} \\
\hline & $\mathrm{CM}$ & $\mathrm{AF}$ & WF & $\mathrm{CM}$ & $\mathrm{AF}$ & WF & $\mathrm{CM}$ & $\mathrm{AF}$ & WF \\
\hline Thr & $146.77 \pm 0.39$ & $123.05 \pm$ & $134.86 \pm$ & $12+030$ & $96.51 \pm$ & $105.77=$ & $1.31=$ & $0.64=$ & 0.65 \\
\hline Lys & $148.84 \pm 0.47$ & $81.45 \pm 1.36$ & $72.44 \pm 1$ & $127.91 \pm c$ & $69.99 \pm$ & $62.25 \pm$ & $1.33 \pm 0.00$ & $0.42 \pm 0.00$ & $0.35 \pm 0.01$ \\
\hline Leu & $101.00 \pm$ & $105.33 \pm 1.64$ & $86.80 \pm$ & $80.34 \pm$ & $83.79 \pm 1.30$ & $69.05 \pm$ & $0.90 \pm 0.00$ & $0.55 \pm 0.01$ & $0.42 \pm 0.02$ \\
\hline Ile & $91.33 \pm 0.17$ & $100.56 \pm 2.78$ & $51.15 \pm 0.80$ & $55.35 \pm 0.10$ & $60.95 \pm 1.68$ & $31.00 \pm 0.49$ & $0.81 \pm 0.00$ & $0.52 \pm 0.02$ & $0.25 \pm 0.00$ \\
\hline Met+Cys & $52.66 \pm 1.59$ & $741.24 \pm 17.92$ & $892.47 \pm 10.28$ & $33.51 \pm 1.14$ & $471.70 \pm 11.40$ & $567.93 \pm 6.54$ & $0.47 \pm 0.02$ & $3.84 \pm 0.04$ & $4.32 \pm 0.04$ \\
\hline Phe+Tyr & $119.77 \pm 0.30$ & $99.64 \pm 1.25$ & $112.46 \pm 0.79$ & $71.86 \pm 0.18$ & $59.78 \pm 0.75$ & $67.47 \pm 0.47$ & $1.07 \pm 0.00$ & $0.52 \pm 0.01$ & $0.54 \pm 0.03$ \\
\hline Val & $125.38 \pm 0.09$ & $100.55 \pm 0.02$ & $96.59 \pm 0.31$ & $85.88 \pm 0.06$ & $68.87 \pm 0.02$ & $66.16 \pm 0.21$ & $1.12 \pm 0.00$ & $0.53 \pm 0.01$ & $0.47 \pm 0.01$ \\
\hline
\end{tabular}

CM, cultured mycelia; AF, artificially cultivated fruiting bodies; WF, wild fruiting bodies. Data were calculated from triplicated samples.

Furthermore, the CSs of Met+Cys in artificially cultivated fruiting bodies and wild fruiting bodies were also much higher than the model values $(55 \mathrm{mg} / \mathrm{g}$ protein).

The RC is used to evaluate the equilibrium of the amino acid. The more scattered the RC is, the greater negative contribution of the amino acids to their equilibrium and the worse nutritional value of the protein will be acquired. The closer the SRC to 100, the higher the nutritional value of protein. The RCs of the amino acids in mycelia, artificially cultivated fruiting bodies and wild fruiting bodies were $0.47-1.33,0.42-3.84$ and $0.25-4.32$, respectively (Table 3). Lys and Met+Cys, Met+Cys and Lys, and Met+Cys and Ile deviated positively and negatively from the amino acid equilibrium spectra of the three types of tested samples, respectively, which was consistent with the AAS results. The second-limiting amino acids in the mycelia, artificially cultivated fruiting bodies, and wild fruiting bodies were Ile, Ile and Lys, respectively, which was consistent with the CS results. The SRC values for the tested samples were 69.84, 25.30 and 46.02, respectively, which were also calculated by the method of Zhu and $\mathrm{Wu}$ [17] and showed significant differences. According to the SRC values, the nutritional value of the proteins in the mycelia was superior to that of the proteins in the artificially cultivated fruiting bodies and wild fruiting bodies. This scattered data may be caused by the high proportion of Met in the artificially cultivated fruiting bodies and wild fruiting bodies, leading to the deviation proportion of essential amino acids in these materials from the $\mathrm{FAO} / \mathrm{WHO}$ reference protein pattern.

\section{EAAI values}

The EAAI is used to estimate the overall effects of all essential amino acids on the tested protein and calculated as the geometric mean of the essential amino acids in the tested protein compared with the reference amino acids in the standard protein patterns (ovalbumin used as standard). The EAAI values of the proteins in mycelia, artificially cultivated fruiting bodies and wild fruiting bodies were $75.15 \pm 0.36,94.43 \pm 1.00$ and $86.31 \pm 1.23$, respectively. The data obtained from this research revealed that the proteins of $G$. gibbosum exhibited a relatively balanced amino acid content, meaning that this species could serve as a favorable source of proteins with suitable proportions.

\section{DISCUSSION}

As a traditional Chinese medicine, Ganoderma possesses important medical and economic value. In this study, the ITS1/ITS4 primers were used to amplify the ITS sequence of a wild macrofungus, 
which was identified by homologous and phylogenetic analysis, combined with its wild morphological characteristics. It was found that the isolated wild strain was G. gibbosum based on classical morphology supplemented by systematic molecular identification [19]. The isolated strain was further cultured in liquid and artificially cultivated, and the amino acid profile and protein quality of the mycelia, artificially cultivated fruiting bodies and wild fruiting bodies were then systematically determined and evaluated according to current international amino acid reference patterns $[20,21]$. The results showed that the crude protein content of the tested G. gibbosum samples was higher than $14 \%$, which is an intermediate level and is higher than those of common cereals such as Oryza sativa L. (7.1-7.7\%) [22], Zea mays L. (10.8\%) [7] and Hordeum vulgare L. (11.2-13.8\%) [23] but lower than those of some common edible fungi (Lentinula edodes (Berk.) Sing 21.4-32.5\%, Pleurotuseryngii (DC.) Quél. 18.6-27.8\%, Agaricusbisporus (J.E. Lange) Imbach 26.5-27.5\%) [18, 24, 25]. The contents of essential amino acids in the proteins of the tested materials were sufficient, and the proportions were basically reasonable, conforming to the requirements of current international reference amino acid patterns.

The total content of essential amino acids in G. gibbosum even exceeded the requirements of the WHO/FAO reference protein pattern value, especially in the artificially cultivated and wild fruiting bodies, which showed much higher contents than the ovalbumin reference protein pattern values. The contents of crude proteins and amino acids are related to the levels of elements such as nitrogen and phosphorus in the environment, and the nutritional value of proteins mainly depends on the species and the quantity and composition ratio of essential amino acids. The AAS and CS of essential amino acids in the artificially cultivated fruiting bodies of G. gibbosum were higher than those in wild fruiting bodies, but the balance of essential amino acids was slightly inferior to that in the wild fruiting bodies. Compared with the research on the total amino acid contents and the total proportion of essential amino acids reported by Chen et al [8], the amino acid contents of G. gibbosum determined in this study were higher, which may be related to the effects on the examined variety and growth conditions.

This study showed that the relative content of lysine was the highest among the essential amino acids in the mycelia, while the relative content of methionine was the highest in the artificially cultivated fruiting bodies and wild fruiting bodies. Lysine plays an important role in promoting human growth and development, enhancing immunity, promoting fat oxidation, and relieving anxiety $[26,27]$. For example, it promotes calcium and iron absorption [28], wound healing and antibody secretion [29]. Methionine is a sulfur-containing amino acid and is closely related to the metabolism of various sulfur-containing compounds in living bodies. Long-term methionine deficiency may cause liver and heart muscle damage [30]. It can also be converted into cysteine or cystine in the body, and the reaction is irreversible [31]. Sulfur-containing amino acids are not only the main donors of sulfur in foods (e.g., providing sulfur atoms for sulfur compounds such as coenzyme A and taurine) but can also inhibit food browning and the Maillard reaction, thereby preventing decreases in food flavor and nutritional value [32]. In addition, sulfurcontaining amino acids such as methionine can produce glutathione (GSH) through the sulfur transfer pathway, thereby achieving oxidation protection in the body $[33,34]$. It is concluded that G. gibbosum presents great potential for the development of functional foods that may promote human growth and development, delay the aging of the body and protect the cardiovascular system.

\section{CONCLUSION}

In the present study, a wild G. gibbosum strain was identified through morphological and molecular analyses and then cultivated artificially. The artificially cultivated fruiting bodies could grow at $25^{\circ} \mathrm{C}$ under $85-95 \%$ relative humidity. The amino acid profile and protein quality of G. gibbosum were systematically investigated according to the most recent version of international reference patterns. The results indicated that the crude protein content of the mycelia of cultivated G. gibbosum was higher than that of artificially cultivated and wild fruiting bodies. The contents of essential amino acids in the proteins of G. gibbosum were sufficient, and the proportions were basically reasonable, conforming to the requirements of current international reference amino acid patterns. In addition, Lys in the mycelia and Met+Cys in the artificially cultivated fruiting bodies and wild fruiting bodies of G. gibbosum were much more plentiful than the model values. In the comprehensive analysis of all indicators, the protein nutritional value of the artificially cultivated fruiting bodies was slightly higher than that of the wild fruiting bodies. In terms of the conservation and rational utilization of medicinal fungal biodiver- 
sity, artificially cultivated G. gibbosum could supply amino acids and protein to humans on a large scale based on the results of this research. In summary, this study provides a theoretical foundation for the exploration and utilization of the nutritional value of $G$. gibbosum in the near future.

Acknowledgements: This work was supported by the "Climbing" Program for Young and Middle-aged Researcher at Shanghai Academy of Agricultural Science (PG18163).

\section{REFERENCES}

1. Dai YC (2009) A checklist of polypores in China. Mycosystema 28, 315-327.

2. Wu XL, Dai YC, Lin YH (2004) Study on the Ganodermataceae of China III. Guizhou Sci 22, 36-40.

3. Wu XL, Song B, Zhao YX, Wen TC, Huang SZ, Lin M (2013) Study on medicinal Ganoderma in China and discussion about name use of Ganoderma spp.. Guizhou Sci 31, 1-17.

4. Zhong JX, Guo JR, Xiao M, Chen HQ, He SZ, Zou FL, Wu XL (1998) Study on the medicinal Ganoderma resources in Hainan island. Chin Pharm J 33, 652-654.

5. Chen XD, Zeng NK, Lan J (2010) Cultural characteristics of mycelia of Ganoderma gibbosum. China $J$ Chin Mater Med 35, 1939-1942.

6. Zhang GG, Lu WP, Lin LZ, Zou JM (2015) Isolation identification, mycelial cultivation characteristics and artificial cultivation of a wild Ganoderma gibbosum strain. North Hortic 22, 153-157.

7. Boye J, Wijesinha-Bettoni R, Burlingame B (2012) Protein quality evaluation twenty years after the introduction of the protein digestibility corrected amino acid score method. Br J Nutr 108, 183-211.

8. Chen TQ, Xu J, Wu JZ (2004) Analysis and comparison of amino acids in the fruitbody of wild and logcultivated Linzhiin in Fujian. Strait Pharm J 16, 1-4.

9. Zhang H, Qin LH, Tan Q, Pan YJ (2006) Extraction of genomic DNA from Lentinula edodes using the CTAB method. J Shanghai Uni (Nat Sci) 12, 547-550.

10. Wagner C, Esbensen KH (2015) Theory of sampling: four critical success factors before analysis. $J$ AOAC Int 98, 275-281.

11. Yu CX, et al (2018) Effects of culture substrates on nutritional and flavor components of Volvariellavolvacea. Mycosystema 37, 1731-1740.

12. Yu WQ, Peng YF, Xu YY, Li J (2015) Analysis and evaluation of nutritional and flavor components and evaluation of five wild dried edible fungi. Nat Prod Res Dev 27, 271-276.

13. WHO/FAO/UNU (2007) Protein and Amino Acid Requirements in Human Nutrition, Report of a joint WHO/FAO/UNU expert consultation, WHO, Geneva, Switzerland.

14. Seligson FH, Mackey LN (1984) Variable predictions of protein quality by chemical score due to amino acid analysis and reference pattern. $J$ Nutr 114, 682-691.

15. Oser BL (1951) Method for integrating essential amino acid content in the nutritional evaluation of protein. J Am Diet Assoc 27, 396-402.

16. Oser BL (1959) An integrated essential amino acid index for predicting the biological value of proteins. In: Protein and Amino Acid Nutrition, Elsevier Inc, pp 281-295.

17. Zhu ST, Wu K (1988) Evaluation of protein nutritional value: method of amino acid ratio coefficient. J Nutr 10, 187-190.

18. Mattila P, Salo-Vaananen P, Konko K, Aro H, Jalava T (2002) Basic composition and amino acid contents of mushrooms cultivated in Finland. $J$ Agric Food Chem 50, 6419-6422.

19. Huang LH, Yang XB, Zhang Z, Hu HP, Zhang YF, Wu QP (2010) Identification of Ganoderma spawns based on ITS sequence analysis. Edible Fungi Chin 29, 55-57.

20. Wu YY, Bao DP, Wang RJ, Chen HY, Wang HM (2018) Amino acids composition and nutritional evaluation of proteins in six samples of cultivated Flammulina velutipes. Food Chem 39, 263-268.

21. Chen HY, Bao DP, Yang RH, Wang Y, Gao YN, Li Y, Wu YY (2019) Amino acid profile and protein quality of Exidia sp. J Nucl Agric Sci 33, 81-87.

22. Mota C, Santos M, Mauro R, Samman N, Matos AS, Torres D, Castanheira I (2016) Protein content and amino acids profile of pseudocereals. Food Chem 193, $55-61$.

23. Xu SJ, et al (2018) Variation characteristics of free amino acids in nutrition organs of Spring Barley and its path analysis with grain protein content. $J$ Nucl Agric Sci 32, 131-140.

24. Chen QL, Li ZH, Chen SQ (2014) Analysis of amino acid composition and nutritional evaluation in five local edible fungus. Food Mach 30, 43-46.

25. Zhang HP, Zhang J, Liu AJ, Zhang P, Sun RG (2013) Analysis of nutritional components and bioactive substances of Pleurotuseryngii. Acta Nutr Sin 35, 307-309.

26. Ghosh S, Pellett PL, Aw-Hassan A, Mouneime Y, Smriga M, Scrimshaw NS (2008) Impact of lysinefortified wheat flour on morbidity and immunologic variables among members of rural families in northwest Syria. Food Nutr Bull 29, 163-171.

27. Smriga M, Ando T, Akutsu M, Furukawa Y, Miwa K, Morinaga Y (2007) Oral treatment with L-lysine and L-arginine reduces anxiety and basal cortisol levels in healthy humans. Biomed Res 28, 85-90.

28. Civitelli R, Villareal DT, Agnusdei D, Nardi P, Avioli LV, Gennari C (1992) Dietary L-lysine and calcium metabolism in humans. Nutr 8, 400-405.

29. Shimomura A, et al (2014) Dietary L-lysine prevents 
arterial calcification in adenine-induced uremic rats. J Am Soci Nephr 25, 1954-1965.

30. Jin HF, Zhao MM, Geng B, Du JB, Tang CS (2012) Endogenous sulfur-containing amino acid metabolism and cardiovascular damage and repair. Phys Sci Progress 43, 330-333.

31. Martinov MV, Vitvitsky VM, Banerjee R, Ataullakhanov FI (2010) The logic of the hepatic methionine metabolic cycle. Biochimi Biophysa Acta 1804, 89-96.

32. Zhao GH, Kan JQ, Chen ZD (1999) The functionality of sulfur-containing amino acid food. Grain Fat 4,
35-37.

33. Mosharow E, Cranford MR, Banerjee R (2000) The quantitatively important relationship between homocysteine metabolism and glutathione synthesis by the transsulfuration pathway and its regulation by redox changes. Biochem 39, 13005-13011.

34. Wang ST, Chen HW, Sheen LY, Lii CK (1997) Methionine and cysteine affect deglutathione level, glutathionerelated enzyme activities and the expression of glutathione S-transferase isozymes in rat hepatocytes. J Nutr 127, 2135-2141. 